\title{
Methods of Improving the Safety of Drilling Works
}

\author{
Zinur Mukhametzyanov ${ }^{1, *}$, Aleksey Rubtsov ${ }^{1}$, and Petr Kulakov ${ }^{1}$ \\ ${ }^{1}$ Ufa State Petroleum Technological University, 450064 Ufa, Russian Federation
}

\begin{abstract}
The article sets the task of developing methods to enhance the safety of drilling operations. The methods should be based on the relationship of technical measures for the mechanization and automation of drilling operations and the level of their safe performance. The measures being developed at oil producing companies to improvement of labor protection conditions and improvement of the labor protection system of most oil producing companies show that the development of such measures does not at all touch upon the issues of enhancing the level of safety during oil production technological processes. Therefore, the task is to maximize the mechanization and automation of these types of work during well drilling in order to increase the safety of their production. Thus, a conceptual approach has been identified for solving the posed problem of increasing the safety of technological processes of oil production. A model has been developed for assessing the effectiveness and efficiency of work safety using a systematic approach to describing the work safety model.
\end{abstract}

\section{Introduction}

In modern conditions, the activities of oil production enterprises have strategic importance for the development of the country. To meet the growing needs of the national economy for the products of the oil-producing complex, the enterprises of the industry are constantly improving and increasing their production, introducing modern efficient technologies for oil production. However, the level of injuries and morbidity among workers of the main specialties in the industry remains quite high, which is the result of a discrepancy between the organization of the labor protection system and production conditions [1-4].

The lack of an integrated, systematic approach to solving the problems of labor protection, the low level of information support does not allow for scientifically grounded planning, determining the most important and paramount areas of preventive work [5-7]. This leads to the development of a large number of ineffective measures, to the irrational distribution and expenditure of funds allocated for labor protection.

Therefore, improving the safety of technological processes of oil production is an urgent task.

\footnotetext{
*Corresponding author: zinur-1966@mail.ru
} 
The development of oil fields is a whole complex of interrelated organizational and technological processes. The life cycle of an oil field includes all stages of technological production - from exploration to liquidation of facilities.

The main process of these stages is well drilling - the process of mechanical destruction of rocks with a special rock-cutting tool, removal of destroyed rock from the bottom of the well and its ascent to the surface [8-9].

\section{Research part}

Drilling oil wells is a complex production process, since the most important technological operations take place in the subsoil. This suggests that there are various options for drilling oil wells and the importance of the human factor - often operational decisions, including those related to ensuring safety, which must be taken in conditions of ambiguity, which may be caused, for example, by a lack of reliable information about bowels. Uncomfortable microclimatic conditions at workplaces, which are almost entirely dependent on the climate in the drilling area, are also unsatisfactory working conditions for the drilling crew.

Based on a quantitative assessment of the risk of each work performed during drilling, performed in terms of the likelihood of the hazard and the severity of its consequences, a work-ranking diagram was obtained (Figure 1).

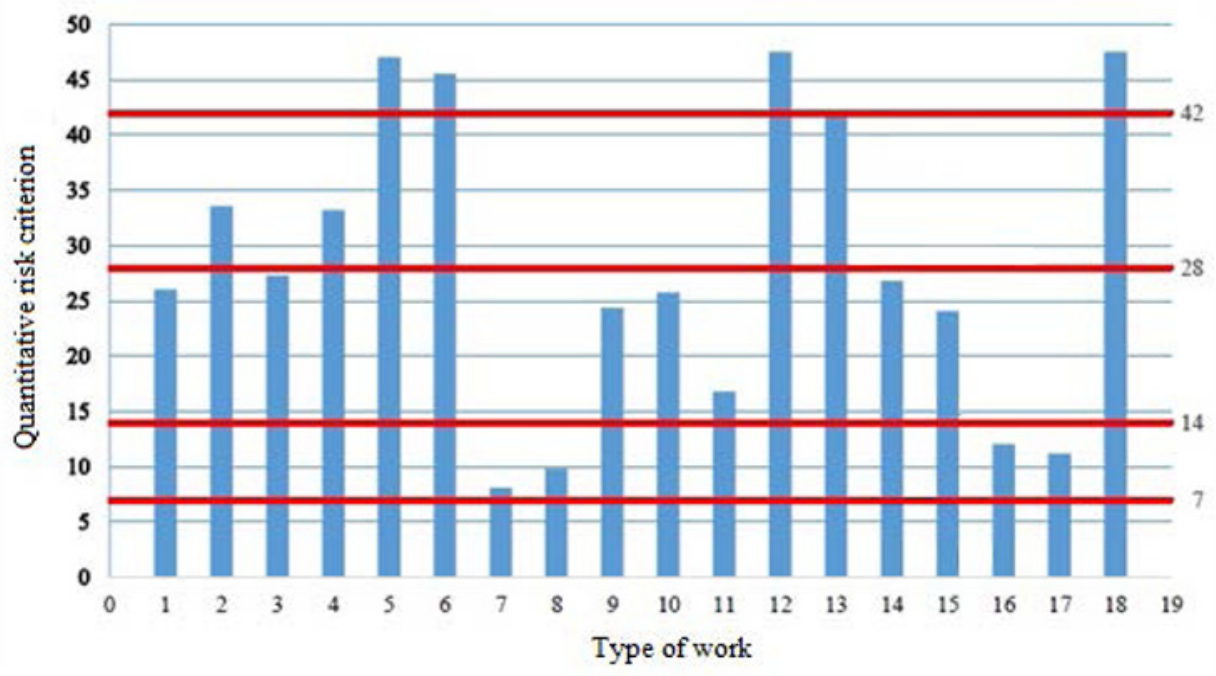

Fig. 1. Diagram of the ranking of works performed during the construction and operation of an oil well by risk level

It can be seen from this diagram that during the construction of the well all work is dangerous and there is no insignificant risk.

Out of 18 types of work during well construction, only four fall under the category of low risk, which is $22 \%$ of the total volume. They are small and usually run remotely.

The average level of risk was identified during seven types of work (39\%). This level of risk is mainly associated with preparatory work associated with delivery, preparation, testing. The main hazards in this case are falling under the transported loads, electric shock, overturning of equipment.

A significant level of risk was assigned to three types of work (17\%): site clearance and leveling, delivery of drilling equipment, and tripping operations. These are lengthy and lengthy processes associated with a large number of people and technology involved. 
Four types of work have a high level of risk (22\%): construction or dragging a tower; installation and installation of drilling equipment on foundations; deepening the wellbore; dismantling of drilling equipment, derrick and near-tower structures. The risk is due to a significant number of operations associated with the installation of equipment at a height, the movement of a large number of different cargo.

The well drilling process itself (wellbore deepening) falls under this risk category due to the likelihood of an uncontrolled release of formation fluid to the surface, as well as an explosion and fire.

Thus, it is required to develop effective safety measures in the production of high-risk operations directly related to the development, maintenance and drilling of wells, i.e. those works that involve the use of a large number of mechanisms and technology.

But the analysis of measures to improve labor protection conditions and improve the labor protection system of most oil-producing companies shows that the development of such measures does not at all touch upon the issues of increasing the level of safety during the technological processes of oil production. Whereas one of the main and defining tasks of the labor protection system at an oil production enterprise should be the task of ensuring and increasing the level of safety in the production of technological processes for oil production [10-12].

According to research and analysis of risk assessments by type of work for the construction and operation of an oil well, four types of work were identified with the highest risk level (22\%). This is building or dragging a tower; installation and installation of drilling equipment on foundations; deepening the wellbore; tripping operations, dismantling of drilling equipment, derrick and near-tower structures. The risk is due to a significant number of operations associated with the installation of equipment at a height, the movement of a large number of different loads, i.e. with the production of work using various means of mechanization and equipment. Out of the listed types of work, tripping operations, as technological operations during the operation of drilling rigs, are the most dangerous in terms of the level of risk of injury. Therefore, the task is to maximize the mechanization and automation of these types of work when drilling wells in order to increase the safety of their production.

Currently, in a complex mechanized way, tripping and hoisting operations are performed only when using drilling rigs (automatic hoisting system) for underground repairs; equipment for this technology is under development.

The presence of automation systems for tripping and lifting operations (automatic hoisting systems) as part of drilling rigs could achieve the following results:

- combine in the time of lowering and lifting the plugs of drill pipes and an unloaded elevator with the installation of the plug on the candlestick and its removal;

- mechanize screwing and unscrewing candles;

- mechanize the installation of candles on the candlestick and their removal to the center of the well;

- mechanize the extension of drill pipes;

- to automate the capture and release of drill pipes by an elevator;

- mechanize lubrication of tool joint threads.

The use of the proposed automatic hoisting systems in the implementation of hoisting operations for the production of drilling operations made it possible to reduce the time of work, which in turn reduced the number of injuries. The resulting dependence is shown in Figure 2.

The implementation of processes for ensuring the safety of production of technological processes in an organization constantly requires an operational assessment of their effectiveness. To do this, it is necessary to develop a specific model that allows for an 
objective and prompt assessment of the implemented measures to improve labor protection conditions.

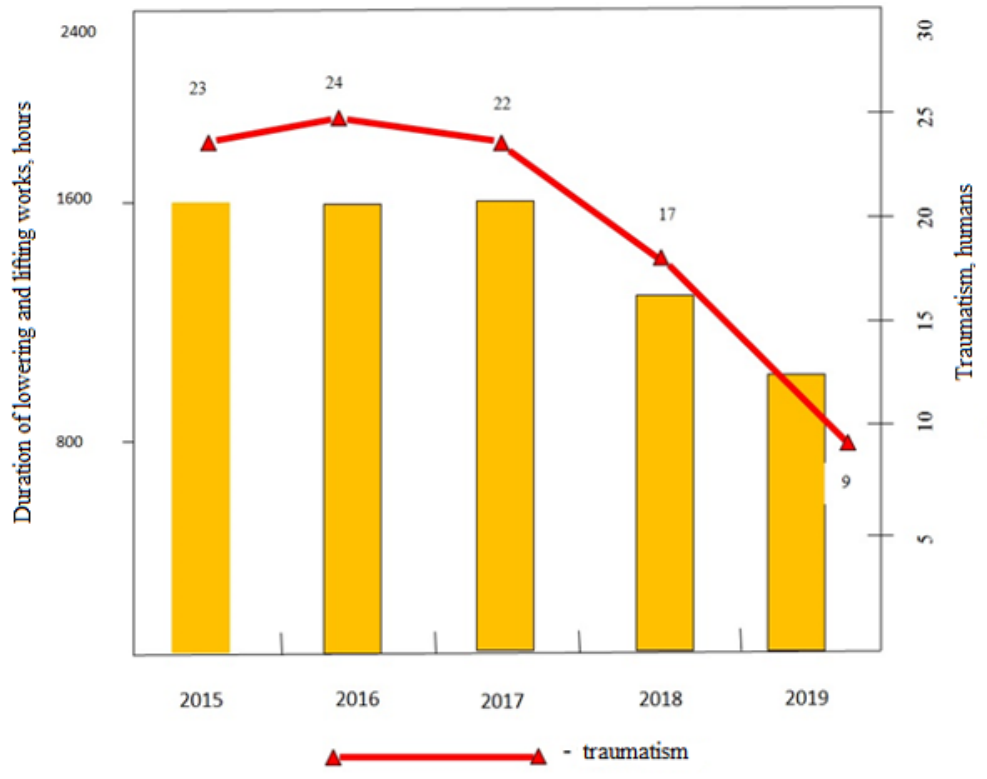

Fig. 2. Dependence of injuries on the implementation of technical measures at an oil production enterprise

To assess the effectiveness and efficiency of work safety after the introduction of technical measures for the mechanization and automation of the main technological operations in oil production in order to increase the safety of drilling operations, a systematic approach to describing the safety of work is the greatest opportunity. The main idea of this approach is to recognize the interrelationships of all elements of the system and the entire system as a whole.

The development of the methodology for the declared assessment consists of the following levels.

Level 1. At this level, the analysis of the main goal and the elements of the second level of the goal tree that affect the improvement of occupational safety is carried out (Figure 3).

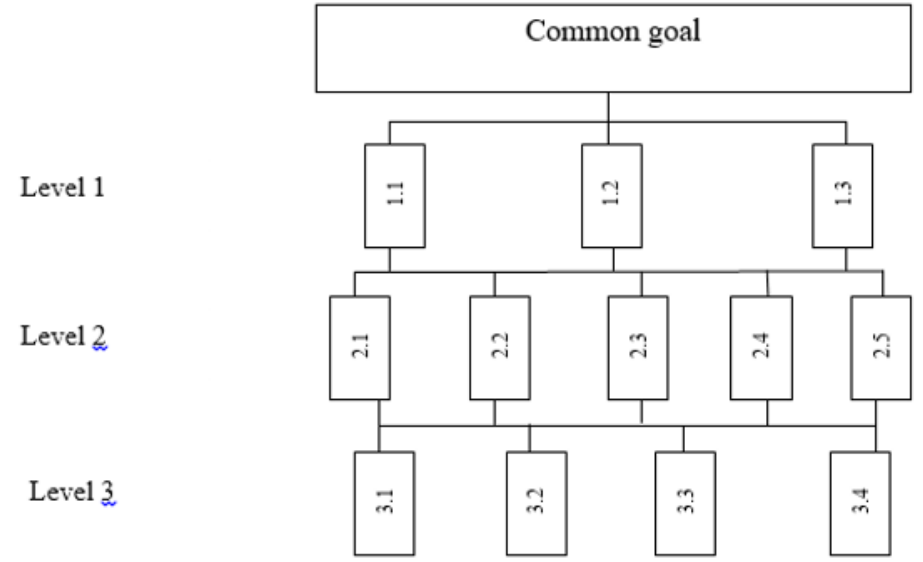

Fig. 3. Decomposition of the task of determining the effectiveness of the labor protection system 
The importance of the lower-level goals for achieving the main goal is assessed using the hierarchy analysis method. The result is a vector $\alpha$ with components $\alpha \mathrm{j}(\mathrm{j}=1,2, \ldots \mathrm{n} \alpha)-\mathrm{a}$ list of lower-level goals that characterize their relative importance for achieving the common goal $\left(\sum_{j=1}^{n_{\alpha}} \alpha_{j}=1\right)$.

The general goal is to assess the level of safety of production of technological processes for oil production

Second level goals:

- reduction of industrial injuries, prevention of occupational diseases;

- ensuring the safety of work processes;

- providing safe workplaces.

Level 2. This level examines the sum of functions and the degree to which they correspond to the objectives of the second level. For this, a modification of the decision matrix method is used. As a result, a list $\beta$ (vector with components $\beta i$. $i=1,2, \ldots n \beta$ ) - is formed - functions of the third level. The task of the experts is to determine the results recorded in Table 1.

Table 1. Matrix for displaying functions on the second level goal.

\begin{tabular}{|c|c|c|c|c|c|}
\hline \multirow{2}{*}{ Functions } & \multicolumn{3}{|c|}{ Goals } \\
\cline { 2 - 6 } & \multicolumn{2}{|c|}{$\mathbf{1}$} & $\ldots$ & \multicolumn{2}{c|}{$\mathbf{n}_{\alpha}$} \\
\hline 1 & $a_{11}^{\beta}$ & $\mu_{11}^{\beta}$ & & $a_{1 n_{\alpha}}^{\beta}$ & $\mu_{1 n_{\alpha}}^{\beta}$ \\
\hline$\ldots$ & & & & $a_{n_{\beta} n_{\alpha}}^{\beta}$ & $\mu_{n_{\beta} n_{\alpha}}^{\beta}$ \\
\hline $\mathrm{n}_{\beta}$ & $a_{n_{\beta 1}}^{\beta}$ & $\mu_{n_{\beta 1}}^{\beta}$ & & & \\
\hline
\end{tabular}

Element $a_{i j}^{\beta}$ - indicator evaluating the relative importance of function $\mathrm{i}$ for goal $\mathrm{j}$ $\left(\sum_{i=1}^{n_{\beta}} a_{i j}^{\beta}=1\right)$.

Element $\mu_{i j}^{\beta}$ - assessment of the quality of function $\mathrm{i}$ to achieve goal $\mathrm{j}\left(0 \leq \mu_{i j}^{\beta} \leq 1\right)$. For scoring it is recommended to use the given scale of qualitative marks (table 2)) [8].

Table 2. Scale of qualitative assessments.

\begin{tabular}{|c|c|}
\hline Assessment value & Qualitative characteristic \\
\hline 1,00 & Best \\
\hline $0,8-1,0$ & Excellent \\
\hline $0,63-0,8$ & Good \\
\hline $0,53-0,63$ & Satisfactory \\
\hline $0,37-0,53$ & Unsatisfactory, in need of improvement \\
\hline $0,2-0,37$ & Critical \\
\hline $0,00-0,2$ & Totally unacceptable \\
\hline
\end{tabular}

To assess the sufficiency of functions to achieve the goals, an additional element is introduced $\mu^{\beta}\left(0 \leq \mu^{\beta} \leq 1\right)$. For scoring it is recommended to use the given scale of qualitative marks (table 2) [14].

The proposed modification of the decision matrix method allows obtaining a dependence characterizing the contribution of functions to the achievement of goals by the formula:

$$
\beta_{i}=\mu^{\beta} \cdot \sum_{j=1}^{n_{\alpha}} a_{i j}^{\beta} \cdot \mu_{i j}^{\beta} \cdot \alpha_{j}
$$

Functions of the labor protection system in an oil company:

2.1 introduction of technical measures for mechanization and automation of technological processes of well drilling; 
2.2 monitoring the implementation of measures for labor protection and safety;

2.3 professional development of employees;

2.4 training of employees on labor protection;

2.5 implementation of measures to improve working conditions developed based on the results of a special assessment of working conditions.

Level 3. At this level, the degree of compliance of the structural units of the labor protection service with the performance of the functions of the labor protection system is investigated. For this, a modification of the decision matrix method is used. As a result, a list vi (vector with components vi. $\mathrm{i}=1,2, \ldots \mathrm{nv}$ ) - structural units is formed. The task of the experts is to determine the results recorded in Table 3.

Table 3. Matrix for mapping structural units to functions of the third level.

\begin{tabular}{|c|c|c|c|c|c|}
\hline \multirow{2}{*}{ Structural units } & \multicolumn{3}{|c|}{ Functions } \\
\cline { 2 - 6 } & \multicolumn{2}{|c|}{$\mathbf{1}$} & $\ldots$ & $a_{1 n_{\beta}}^{v}$ & $\mu_{1 n_{\beta}}^{v}$ \\
\hline 1 & $a_{11}^{v}$ & $\mu_{11}^{v}$ & & & \\
\hline$\ldots$ & & & & $a_{n_{\nu} n_{\beta}}^{v}$ & $\mu_{n_{\nu} n_{\beta}}^{v}$ \\
\hline $\mathrm{n} v$ & $a_{n_{1}}^{v}$ & $\mu_{n_{\nu 1}}^{v}$ & & \\
\hline
\end{tabular}

Element $a_{i j}^{v}$ - indicator evaluating the relative importance of structural unit i for function $\mathrm{j}\left(\sum_{i=1}^{n_{\beta}} a_{i j}^{v}=1\right)$.

Element $\mu_{i j}^{v}$ - assessment of the quality of work of structural unit $\mathrm{i}$ to achieve function $\mathrm{j}$ $\left(0 \leq \mu_{i j}^{v} \leq 1\right)$. For scoring it is recommended to use the scale of qualitative assessments (table 3) [15].

To assess the sufficiency of structural units to achieve functions, an additional element is introduced $\mu^{v}\left(0 \leq \mu^{v} \leq 1\right)$. For scoring it is recommended to use the scale of qualitative assessments (table 2) [13-15].

The proposed modification of the decision matrix method allows obtaining a dependence characterizing the contribution of structural units to the implementation of functions according to the formula:

$$
v_{i}=\mu^{v} \cdot \sum_{j=1}^{n_{\beta}} a_{i j}^{v} \cdot \mu_{i j}^{v} \cdot \beta_{i}
$$

Structural units:

\subsection{Head of Department.}

3.2 Deputy Head of Department.

3.3 Department for labor protection, industrial safety and environmental protection.

3.4 Health, safety and environment sector for work with the Customer.

Level 4. At this level, an assessment of the effectiveness of the labor protection system to improve the safety of drilling operations is determined.

For this, it is proposed to implement the additive convolution of the vector $v$ :

$$
C=\sum_{i=1}^{n_{v}} v_{i}
$$

To obtain a qualitative assessment, it is proposed to use the reduced scale of qualitative assessments (table 2) [8].

The labor protection system proposed in the work in an oil production company with the introduced technical measures for the mechanization and automation of technological operations for drilling wells was evaluated according to the proposed method.

The calculation was carried out using Excel spreadsheets (Table 4).

The obtained result $\mathrm{C}=0.648875$ corresponds to the "good" indicator on the scale of qualitative characteristics. 
Table 4. Assessment of the effectiveness of the labor protection system to improve the safety of drilling operations

\begin{tabular}{|c|c|c|c|c|c|c|c|c|c|c|c|}
\hline Goals & 1 & 2 & 3 & & & & & & & & \\
\hline Importance & 0,2 & 0,4 & 0,4 & & & & & & & & \\
\hline \multicolumn{12}{|c|}{ Goals } \\
\hline & 1 & & 2 & & 3 & & & & & & \\
\hline 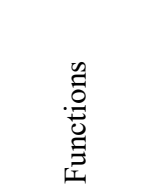 & 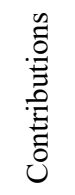 & 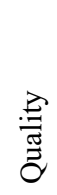 & 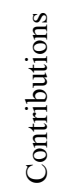 & $\frac{\vec{Z}}{\stackrel{\Xi}{\Xi}}$ & 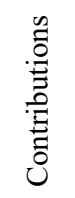 & 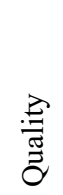 & 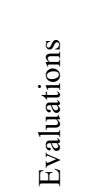 & & & & \\
\hline 1 & 0,1 & 0,9 & 0 & 0 & 0,4 & 0,8 & 0,1314 & & & & \\
\hline 2 & 0,2 & 1 & 0,3 & 1 & 0 & 0 & 0,144 & & & & \\
\hline 3 & 0,2 & 0,7 & 0 & 0 & 0 & 0 & 0,0252 & & & & \\
\hline 4 & 0,5 & 1 & 0 & 0 & 0,4 & 0,9 & 0,2196 & & & & \\
\hline 5 & 0 & 0 & 0,7 & 0,8 & 0,2 & 1 & 0,2736 & & & & \\
\hline Total & 1 & & 1 & & 1 & & 0,7938 & & & & \\
\hline \multirow{2}{*}{\multicolumn{12}{|c|}{ Overall score 0,9}} \\
\hline & & & & & & & & & & & \\
\hline 莺 & 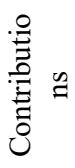 & 坣 & 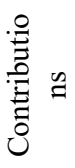 & 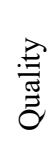 & 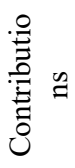 & 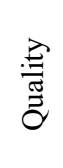 & $\begin{array}{l}\stackrel{0}{\Xi} \\
\stackrel{0}{\Xi} \\
\text { 泀 }\end{array}$ & 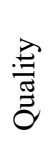 & 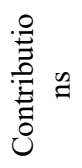 & 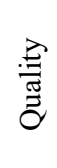 & 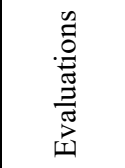 \\
\hline 1 & 0,3 & 0,8 & 0 & 0 & 0,3 & 0,9 & 0,2 & 0,8 & 0,1 & 0,9 & 0,08829 \\
\hline 2 & 0,3 & 1 & 0,5 & 1 & 0 & 0 & 0,2 & 1 & 0,5 & 1 & 0,262926 \\
\hline 3 & 0 & 0,9 & 0,4 & 0,9 & 0 & 0 & 0,3 & 0,7 & 0,4 & 0,8 & 0,209531 \\
\hline 4 & 0,4 & 0 & 0,1 & 1 & 0,7 & 1 & 0,3 & 1 & 0 & 0 & 0,088128 \\
\hline Total & 1 & & 1 & & 1 & & 1 & & 1 & & 0,648875 \\
\hline \multicolumn{4}{|c|}{ Overall score 0,9} & & & & & & & & \\
\hline
\end{tabular}

The result obtained using the developed model for assessing the effectiveness and efficiency of work safety corresponds to the results of the analysis of statistical data (Figure 2 ), which indicates the adequacy of the model to real situations and the possibility of its further application to assess the effectiveness and efficiency of work safety in oil companies.

\section{Findings}

One of the main directions for improving the safety of work at oil production enterprises is the technical and technological improvement of drilling operations.

For an objective assessment of the safety of drilling operations, it is advisable to use, on the basis of a system analysis, a quantitative assessment of the safety efficiency of operations at oil producing enterprises.

\section{References}

1. S.Martinez-Lopez, V. Upasani, S. Pandanaboyana, P.Lodge, E. Hidalgo, International Journal of Surgery 44, 82-86 (2017)

2. E.V. Shchekina, IOP Conference Series: Materials Science and Engineering 1001(1),012117 (2020) 
3. M.S. Hashem M. Mehany, J. Killingsworth, S. Shah International Journal of Construction Education and Research, 17(1), 18-36 (2021)

4. I.A. Efremova, B.A. Anfilofev, Bezopasnost' Truda v Promyshlennosti, 2020(6), 79-83 (2020)

5. C.Robbe, A.Papy, N. Nsiampa, Human Factors and Mechanical Engineering for Defense and Safety, 3(1), 3 (2019)

6. I.A. Efremova, B.A. Anfilofev, Bezopasnost' Truda v Promyshlennosti, 2020(6), 79-83 (2020)

7. Z.R. Mukhametzyanov, P.A. Kulakov, A.V. Rubtsov, Journal of Physics: Conference Series, 1582(1),012054 (2020)

8. X. Wang, D. Zou, Fresenius Environmental Bulletin, 29(12), 10707-10711 (2021)

9. A.V. Milkov, Journal of Petroleum Science and Engineering 204, 108754 (2021)

10. A.A. Matveeva, E. Ladonina, O. Popova, IOP Conference Series: Materials Science and Engineering, 483(1),012113 (2019)

11. G.N. Kinghabaeva, Y.N. Savicheva, IOP Conference Series: Earth and Environmental Science 677(5),052055 (2021)

12. D.M. Kostin, B.V. Sevastyanov, R.O. Shadrin, IOP Conference Series: Materials Science and Engineering, 687(6), 066047 (2019).

13. Z.R. Mukhametzyanov, P.A. Kulakov, A.V. Rubtsov, Journal of Physics: Conference Series, 1515(4),042006 (2020)

14. A.R. Maskova, G.U. Yarmuhametova, Y.N. Savicheva, Materials Science Forum, 992 MSF, 359-363 (2020)

15. N.V. Vadulina, N.K. Abdrahmanov, A.V. Fedosov, Y.N. Savicheva, I.D. Khlopina, IOP Conference Series: Materials Science and Engineering 862(4), 042040 (2020) 